\title{
A única intuição - o único pensamento: Sobre a questão do sistema em Fichte e em Schopenhauer ${ }^{1}$
}

Matthias Koßler

Universidade de Mainz

resumo No artigo que se segue, iremos relacionar o tema "intuição“ e „pensamento“ ao problema, virulento no idealismo alemão, da sistemática filosófica. Depois que a concepção kantiana de sistema assente na "Arquitetônica da razão" foi criticada como formalista e que, ao mesmo tempo, se propagou no século XVIII a crítica aos sistemas racionalistas, exercida antes pelo empirismo, irrompeu no final desse século uma crise na filosofia, expressa talvez de modo mais marcante em um "fragmento" de Friedrich Schlegel: "É igualmente mortal ao espírito ter um sistema e não ter nenhum". Fichte e Schopenhauer tratam da questão do sistema reportando-a à relação entre intuição e pensamento.

palavras-chave Schopenhauer; Fichte; pensamento; intuição

\section{Introdução}

A relação entre intuição e pensamento é tema que está no centro da teoria do conhecimento, da doutrina das idéias de Platão à especulação na Idade Média e ao conflito entre empirismo e racionalismo na Idade Moderna até o debate sobre "Imagery" na neurofilosofia contemporânea. O idealismo alemão representa, nesse desdobramento, um movimento contrário à tentativa de Kant de separar intuição e pensamento com base nos dois "troncos" da faculdade de conhecimento, sensibilidade e entendimento. Como intuição intelectual em Fichte e em Schelling, como conceber especulativo em Hegel e como intuição

Recebido em 18 de outubro de 2006. Aceito em 20 de dezembro de 2006.

Tradução: Paulo R. Licht dos Santos - UFSCar. Revisão: André Carone - UFSCar.

doispontos, Curitiba, São Carlos, vol. 4, n. 1, p. 153-173, abril, 2007 
154

intelectual em Schopenhauer, intuição e conceito convergem para uma unidade que só internamente ainda poderia ser distinguida.

No que se segue, iremos relacionar o tema "intuição e pensamento", a perder de vista em seu significado epistemológico e histórico-filosófico geral, com o problema, virulento no idealismo alemão, da sistemática filosófica. Depois que a concepção kantiana de sistema assente na "Arquitetônica da razão" foi criticada como formalista (cf. o artigo “System”, in RITTER E GRÜNDER, 1971. Col. 840) e que, ao mesmo tempo, se propagou no século XVIII a crítica aos sistemas racionalistas, exercida anteriormente pelo empirismo (cf. op. cit., col. 825, em partic. col.. 832), irrompeu no final desse século uma crise na filosofia, expressa talvez de modo mais marcante em um "fragmento" de Friedrich Schlegel: "É igualmente mortal ao espírito ter um sistema e não ter nenhum. Assim, terá de decidir-se a ligar ambos" (SCHLEGEL, 1980. vol. 1, p. 196) ${ }^{2}$. Fichte e Schopenhauer tratam da questão do sistema reportando-a à relação entre intuição e pensamento.

Que a relação entre intuição e pensamento esteja ligada imediatamente à problemática do sistema do saber, pode-se ver a partir da crítica já mencionada aos sistemas do racionalismo. Um sistema de saber só pode aspirar a ser saber se a ele corresponder uma concatenação sistemática no mundo real (Cf. o artigo "System", in RITTER E GRÜNDER, 1971. Col. 853). O racionalismo pressupõe que o mundo, como criação de Deus, exibe uma ordem racional e que a razão humana possui uma continuidade com a razão criadora divina. O empirismo, que contesta ao menos este último ponto, não deixa subsistir a relação do sistema do saber com a realidade. Aqui, a realidade se manifesta apenas de maneira contingente mediante a sensibilidade. Em Kant, a referência à ordem divina dá lugar à orientação para o fim último moral, que fundamenta a validade do sistema e torna possível a filosofia de acordo com o seu "conceito cósmico" (KANT, 1968.Vol. 3, p. 542). Na comparação a seguir entre Fichte e Schopenhauer, essa referência à moral e o desdobramento, acima mencionado, da concepção da relação entre intuição e pensamento devem ser considerados um pano de fundo histórico.

doispontos, Curitiba, São Carlos, vol. 4, n. 1, p. 153-173, abril, 2007 


\section{Dois textos sobre a questão do sistema}

De início, confrontemos duas passagens que se ocupam com a questão do sistema da filosofia.

O primeiro texto provém da Exposição da Doutrina-da-Ciência de Fichte, dos anos 1801-1802:

A despeito de a Doutrina-da-Ciência não ser um sistema de conhecimentos, mas uma intuição una [Einige Anschauung], poderia bem ser, no entanto, que a unidade dessa intuição, longe de ser uma simplicidade absoluta, um elemento último, átomo, mônada ou como ainda se queira exprimir esse não-pensamento, porque algo assim certamente não existiria no saber nem em lugar algum, seja uma unidade orgânica, uma fusão da multiplicidade na unidade e, ao mesmo tempo, uma dispersão da unidade na multiplicidade e precisamente numa unidade indivisa [...].

Além do mais, no caso de passar-se assim, poderia perfeitamente acontecer, não no que diz respeito à posse dessa ciência, que se deve pressupor em nós, mas à exposição dela para outros que se pressupõe que não a possuem, que não pudéssemos expor imediatamente aquela unidade, mas que, ante o olhar do leitor, tivéssemos primeiro de deixála organizar-se a partir de qualquer multiplicidade e de novo desorganizar-se nesta. Nesse caso, o membro do múltiplo a partir do qual a nossa organização teria começado não seria inteligível como membro isolado, uma vez que por si não é nada, mas só é inteligível como parte orgânica de uma unidade e só na unidade o pode ser. Jamais conseguiríamos, pois, uma entrada para a nossa ciência, ou se a conseguíssemos, e se uma parte isolada pudesse tornar-se inteligível, isso só poderia acontecer porque a sua intuição estaria acompanhada pela intuição do todo, ainda que obscura e sem dela estarmos conscientes $[\ldots]$.

Podemos acrescentar, de um ponto de vista histórico, que efetivamente se passa assim como foi suposto por nós, e que é dessa maneira que é determinado o método da Doutrina-da-Ciência. Essa ciência não é uma progressão dedutiva numa série simples, como que numa linha, segundo a lei da consequiência, procedimento esse que, sendo possível somente no interior de e sobre um organismo de saber já pressuposto e 
subjacente, em filosofia não leva a nada e nesta é a própria superficialidade; mas é dedutiva por todos os lados e de modo recíproco, partindo sempre de um ponto central para todos os pontos e retornando de todos os pontos, como que num corpo orgânico (FICHTE, 1964.V. II, 6, p.141-143. Cf. tb. SCHOPENHAUER, 1985. Vol. II, p. 90) ${ }^{3}$.

O segundo texto é extraído do prefácio à primeira edição de $O$ mundo como vontade e representação de Schopenhauer, de 1818:

Aqui me proponho a indicar como este livro deve ser lido para eventualmente poder ser compreendido. - O que deve ser compartilhado ${ }^{4}$ por ele é um único pensamento [ein einziger Gedanke]: contudo, a despeito de todos os esforços, não o pude compartilhar por nenhum caminho mais curto senão por este livro inteiro.- [...].

Segundo o ponto de vista de que é considerado, esse único pensamento a ser compartilhado se mostra como aquilo que é chamado de metafísica, de ética, de estética; e não há dúvida de que também deva ser tudo isso se for tal como já declarei que o concebo. Um sistema de pensamentos tem de ter invariavelmente uma correlação arquitetônica, i. e., uma correlação tal em que uma parte sempre sustenta a outra, não sendo esta, porém, sustentada por aquela, por fim a pedra fundamental sustenta todas as partes sem por elas ser sustentada, a cúpula é sustentada sem sustentar. Em contraposição, um único pensamento, por mais abrangente que seja, tem de guardar a mais perfeita unidade. Todavia, caso se possa decompô-lo em partes, com o objetivo de compartilhá-lo, a concatenação dessas partes tem de ser, mais uma vez, uma correlação orgânica, i. e. uma correlação tal em que cada parte tanto mantém o todo quanto é sustida pelo todo, em que nenhuma parte é a primeira e nenhuma é a última, em que o pensamento inteiro ganha em distinção em virtude de cada parte, e também a parte mais diminuta não pode ser plenamente entendida sem que antes se entenda o todo. - Um livro, entretanto, tem de ter uma primeira e uma última linha e, nessa medida, sempre será muito dessemelhante a um organismo, por mais que seu conteúdo possa alguma vez se assemelhar a ele: por conseguinte, forma e matéria estarão aqui em contradição (SCHOPENHAUER, 1972.Vol. II, p.VII) ${ }^{5}$. 
Encontram-se no texto de Schopenhauer, caso não se leve em conta o modo de expressão mais conciso, paralelos com todos os pontos essenciais dos dois primeiros parágrafos do texto citado de Fichte: ambos os filósofos distanciam-se - desde logo - da concepção de sistema caracterizada pela aceitação de uma "pedra fundamental" ou de um "elemento último", ao qual se referem como a seu fundamento todos os demais conhecimentos ou pensamentos. Ambos propõem, ao contrário, a idéia de uma unidade "orgânica". Para Fichte, subjaz a essa unidade "uma intuição una”, para Schopenhauer, "um único pensamento”. Ambos novamente argumentam, a partir da unidade orgânica, que o próprio pensamento ou a intuição não têm partes, mas é o compartilhá-los que torna necessário que tenham partes, nenhuma das quais, porém, é compreensível sem as demais, de sorte que a compreensão do todo pelo leitor ou pelo ouvinte já tem de ser pressuposta desde o início.

Se tomarmos outra passagem dos Parerga e Paralipomena de Schopenhauer, também é possível verificar uma concordância em recusar a conseqüência lógica e linear como meio apropriado de exposição:

Minhas proposições, ao contrário, repousam o mais das vezes não sobre cadeias de raciocínios, mas sobre o próprio mundo intuitivo, e a rigorosa conseqüência encontrada no meu sistema, assim como em qualquer outro, não é alcançada, via de regra, por um caminho meramente lógico; ela é, antes, a concordância natural de proposições que inevitavelmente surge por estarem todas fundadas sobre a apreensão intuitiva do mesmo objeto, considerado apenas de diferentes perspectivas, fundadas, portanto, sobre a apreensão intuitiva do mundo real em todos os seus fenômenos, observados pela consciência na qual este mundo se apresenta (SCHOPENHAUER, 1972.Vol.V, p. 140).

Não se trata de afirmar que há uma influência direta da passagem citada de Fichte em Schopenhauer. Dificilmente se poderá esclarecer se este conheceu o escrito de Fichte em 1818 ou em $1816^{6}$ (talvez em circulação na forma de manuscrito), escrito que foi impresso pela primeira vez em 1845/46. Mas não há dúvida de que, por ter freqüentado as aulas de Fichte durante os seus estudos em Berlim em 1811-1813, Schopenhauer estava familiarizado com o pensamento e com o método de Fichte. Sabese mesmo que uma das muitas versões da Doutrina-da-Ciência, a dupla

doispontos, Curitiba, São Carlos, vol. 4, n. 1, p. 153-173, abril, 2007 
preleção Sobre os fatos da consciência e a Doutrina-da-Ciência de 1811-1812, chegou até nós pela cópia de Schopenhauer (SCHOPENHAUER, 1985. Vol. II, p. 16-216). Sevir-me-ei dela, ao lado da citada Doutrina-daCiência de 1801-1802, porque as observações e os comentários adicionados por Schopenhauer iluminam a maneira e o modo como se deu a sua recepção de Fichte. Em geral, pode-se dizer que Schopenhauer, que mais tarde em seus escritos publicados insultou Fichte chamando-o sobretudo de "fanfarrão", foi um ouvinte extremamente atento e sério 7 , que, no entanto, logo traduzia o que ouvia para o seu pensamento intuitivo, ligando-o a uma ordem de idéias já existente. A exposição abstrata e dura de Fichte não era nada para Schopenhauer, que diz em seu tratado Sobre o escrever e o estilo: "Aos escritores alemães caberia compreender de uma vez por todas que, sempre que possível, se deve pensar como um grande espírito, mas se deve falar a mesma língua, como qualquer um. Servir-se de palavras comuns e dizer coisas incomuns" (SCHOPENHAUER, 1972, vol. VI, p. 554). Assim, desde cedo ele começa a munir suas anotações com observações e citações tais como: "É usual que o homem acredite, tão logo ouve palavras, que por elas também se deve poder pensar algo" (SCHOPENHAUER, 1972, vol. VI, p. 29, 107) . Não $^{2}$ obstante, Schopenhauer assistiu ao curso inteiro e jamais deixou de justificar a ausência de um registro9.

Aqui se deve fazer, pois, uma comparação menos do ponto de vista da recepção histórica do que uma comparação que tem muito mais em vista como projetos de sistemas tão distintos puderam ser desenvolvidos com base em suposições metodológicas fundamentais que concordam quase literalmente. Para retornar às duas citações, antes de tudo se vê, em todos os pontos concordantes, que aquilo que constitui a unidade da correlação orgânica se chama, para Fichte, "intuição", ao passo que, para Schopenhauer, "pensamento". Isso talvez pareça apontar para uma diferença de concepção, na medida em que a intuição se aproxima de uma correlação estática, tal qual uma "imagem", enquanto o pensamento discursivo faz supor uma unidade como movimento e processo. A favor disso também falaria o modo como Schopenhauer critica, em um manuscrito da época de seus estudos de Fichte, o método deste: "Fichte e Schelling pisam o entendimento, declarando-o não emancipado, [...], assim, a partir da intuição, fazem revelações sem fundamentos e não levam em conta que a sua

doispontos, Curitiba, São Carlos, vol. 4, n. 1, p. 153-173, abril, 2007 
doutrina contradiz as leis fundamentais do entendimento" (SCHOPENHAUER,1985, vol.V, p. 20; cf. p. 138) ${ }^{10}$.

Todavia, a diferença entre Fichte e Schopenhauer não se deixa apanhar tão facilmente. A passagem citada dos Parerga e Paralipomena contradiz a crítica de Schopenhauer quando, nessa obra, a forma do entendimento é subordinada à apreensão intuitiva e ordenada segunda ela. E, em outra passagem, Schopenhauer diz que a unidade do único pensamento [die Einheit des Einen Gedankens] provém da "harmonia e unidade do próprio mundo intuitivo" (Schopenhauer:1972.Vol.I, p. 99). Fichte, por sua vez, acentua que a única intuição [Eine Anschauung], na condição de conhecimento, é um pensamento (FICHTE,1964.Vol. II, p. 162). Ao falar de um único pensamento, Schopenhauer poderia até mesmo estar retomando imediatamente Fichte, que diz em sua preleção de 1811: “[...] a Doutrina-da-Ciência é compartilhada como uma série de muitos pensamentos, embora seja, na verdade, apenas um único pensamento" (SCHOPENHAUER, 1985.Vol.II, p. 27). A dificuldade em estabelecer a diferença está atrelada à coincidência, acima mencionada, entre intuição e pensamento.

A fim de elaborar a comparação entre as duas concepções de sistema e expor a diferença realmente significativa, temos de passar da consideração meramente formal para a consideração do conteúdo. Isso também é palpável, visto que os sistemas que repousam de tal modo sobre uma correlação orgânica só podem mostrá-la por uma elaboração concreta. Deve ser investigado, assim, o que em cada um se deve entender por intuição e pensamento, como se deve determinar a relação entre este e aquela e como isso afeta a sistemática e os resultados da doutrina filosófica. É natural que isso só possa ser feito, aqui, de maneira abreviada, com o intuito de assinalar, em grandes traços, possíveis paralelos ou diferenças.

\section{Intuição e pensamento em Fichte}

A "única intuição" [die eine Anschauung], que constitui a Doutrina-daCiência de Fichte, é intuição do saber, o qual é determinado, por sua vez, como uma "intuição una" [einige Anschauung]. A Doutrina-da-Ciência é saber do saber ou intuição da intuição. O conceito de intuição é desprendido da percepção, que se refere ao particular no espaço e no tempo, 
enquanto a intuição como saber abrange em "um único olhar" ["in Einem Blike"] todo o representar em vista de um objeto - e este é, na Doutrina-da-Ciência, o próprio saber (FICHTE, 1964.Vol.II, p. 137 e ss. Cf. SCHOPENHAUER, 1985. Vol.II, p. 34 e p. 22)11. Esse um único olhar - a intuição - é caracterizado como um "oscilar" entre determinações (Fichte:1964. Vol. II, p. 152, 156). A intuição, como oscilar, mantém juntos unidade e multiplicidade, ser e liberdade, de maneira tal que nenhum lado possui consistência; mas precisamente assim se torna possível uma unidade na qual um lado não é subsumido pelo outro ${ }^{12}$. O pensar tem, em Fichte, a função de fixar as determinações que estão mantidas juntas na intuição e, com isso, levar o oscilar entre eles ao repouso e à unidade (Fichte:1964.Vol. II, p. 155, 162 e ss., p. 216).

Acrescentando-se o pensar à intuição, vêm então à luz do saber os momentos mantidos juntos pela intuição, ser e liberdade, (i. e., mediante o pensamento vem-se a saber, então, o que a intuição contém em si). $\mathrm{O}$ pensar mostra-se como parte integrante necessária da intuição, que, se deve ser saber, tem de tornar-se "auto-intuição" do saber (FICHTE, 1964.Vol. II, p. 169). Na auto-intuição, o saber se opõe a si na forma da egoidade apenas pensada (FICHTE,1964. Vol. II, p. 150, 166; cf. SCHOPENHAUER, 1985. Vol. II, p. 45, 62 e ss). O procedimento ulterior consiste em análises dessa reflexão do saber (FICHTE, 1964.Vol. II, p. 168), pelas quais se mostra que o saber não é mera intuição, mas a unificação de intuir e pensar. Essa reflexão é tomada como "intuição superior", que se opõe à intuição "fática" (o saber fático) (FICHTE, 1964. Vol. II, p. 186). A intuição superior reflete, uma vez que contém o pensar, a fusão intuída da multiplicidade e a dispersão da unidade como atividade. Para a intuição superior - não para a fática - o eu que age produz a passagem da determinabilidade para a determinação no saber (FICHTE, 1964. Vol.II, p 216 ss) ${ }^{13}$. Isso acontece primeiro como impulso e sentimento (FICHTE, 1964.Vol.II, p. 290, cf. 193. Cf. SCHOPENHAUER, 1985. Vol. II, p. 58 ss). Aqui é contingente qual determinidade é posta no domínio infinito do determinável; a liberdade do eu é aqui somente formal: a possibilidade de pôr ou de não-pôr uma dada determinidade, e dessa maneira é produzido o mundo contingente, mutável (FICHTE, 1964.Vol.II, p. 184 ss. Cf. SCHOPENHAUER, 1985.Vol. II, pp. 66 - 71). Porém, visto que a liberdade meramente formal não é liberdade no saber, 
no qual ela se vincula ao ser, então o mundo contingente é um nada para o saber ${ }^{14}$. O mundo verdadeiro é o mundo em que o agir é determinado por uma lei interna. A legalidade no agir conduz ao caráter e ao conceito de vontade (Fichte:1964.Vol.II, p. 316, 318 s; Schopenhauer: 1985.Vol. II, p. 173 ss., particularmente p. 213 ss), à qual corresponde o sentimento já não o de ser impelido, mas o de estar obrigado, o sentimento de responsabilidade ou consciência (FICHTE, 1964.Vol.II, p. 321, cf. p. 196. Cf. SCHOPENHAUER, 1985.Vol.II, p. 76 ss).

Desse modo se chega ao ponto final da Doutrina-da-Ciência, a partir do qual unicamente se mostra a compreensão integral das partes antecedentes. Assim, o mundo que em si é um nada e contingente só tem consistência e significado pelo mundo moral. Sua intuição fática, que era, como o saber, o ponto de partida, apenas se efetiva pelo "esquecimento" da reflexão ${ }^{15}$. Mas, inversamente, a intuição fática é a pressuposição para que o pensamento possa "desembaraçar-se" dela na reflexão, a fim de tornar-se intuição "superior” (FICHTE, 1964. Vol.II, p. 164. Cf. SCHOPENHAUER, 1985.Vol. II, p. 42, 48, 72 s). A intuição intelectual é, assim, o "ponto central" no qual se correlacionam a intuição fática e a superior. Mas essa correlação ou passagem não se dá nem na intuição nem no pensamento, mas pela liberdade. Esta pressupõe, como diz Fichte na preleção de 1811, uma "lucidez absoluta" [absolute Besonnenheit] (SCHOPENHAUER, 1985.Vol.II, p. 27 s., 38).

\section{Intuição e pensamento em Schopenhauer}

As menções de Schopenhauer ao "um único pensamento" - à parte a passagem citada e uma referência a ela no quarto livro de sua obra principal (SCHOPENHAUER, 1972.Vol. I, p. 337) ${ }^{16}$ - são escassas; apenas há alusões isoladas à correlação orgânica. Encontra-se a seguinte observação no manuscrito da época da composição do Mundo como vontade e representação: "Toda a minha f[ilosofia] pode ser resumida numa expressão: o mundo é o autoconhecimento da vontade" (SCHOPENHAUER, 1985. Vol. I, p. 462). Não se trata, pois, como em Fichte, de uma auto-intuição do saber, mas do autoconhecimento da vontade. Para Schopenhauer, não pode haver uma auto-intuição do saber, porque o sujeito cognoscente 


\section{2}

jamais pode tornar-se objeto de conhecimento, pois ele é o correlato necessário do objeto (SCHOPENHAUER, 1985.Vol.II, p. 68). Já em suas anotações sobre o curso de Fichte, Schopenhauer havia escrito: "Só há um quem intui, o eu: e, justamente por isso, este não é jamais um intuído" (SCHOPENHAUER, 1985. Vol.II, p. 68). Parece uma réplica a Fichte que o sistema de Schopenhauer comece com a exposição do mundo como representação, na qual se mostra, antes de tudo, que o conhecimento se decompõe em sujeito e objeto e está sob o princípio de razão. De acordo com isso, também a intuição é determinada pelo princípio de razão, cujo correlato, pela parte do sujeito, é o entendimento. Nesse sentido, para Schopenhauer, “toda intuição é intelectual”, mas é nítido que essa expressão possui um significado completamente diverso da intuição intelectual em Fichte ${ }^{17}$. A intuição refere-se ao objeto da experiência e às ciências empíricas. O pensamento conceptual, por sua vez, refere-se à intuição de modo subordinado, pois os conceitos, como "representações de representações", são derivados das representações intuitivas (SCHOPENHAUER, 1972. Vol. I, p. 48). O pensamento pressupõe a intuição empírica, da qual recebe todo o conteúdo. Schopenhauer atribui-se o mérito particular de ter exposto distintamente a diferença, antes dele tão pouco notada, entre conhecimento intuitivo e conhecimento abstrato (SCHOPENHAUER, 1972.Vol. I, p. 452, Vol. II, p. 96).

A primeira consideração do mundo como representação é, como Schopenhauer logo enfatiza, uma "abstração arbitrária”, que foi empreendida com o objetivo de compartilhar o pensamento (SCHOPENHAUER, 1972. Vol. I, p. 5). A mera rede de relações que constitui o mundo sob o princípio de razão deixa irromper em suas lacunas o infundado, as impressões e as forças dadas (qualidades). Essa lacuna é preenchida quando a vontade, experimentada internamente no próprio corpo, é transposta por analogia a todas às representações como o ser interno delas ${ }^{18}$. A vontade é, então, em oposição ao conceito de vontade de Fichte, simplesmente o que é desprovido de fundamento e de lei, precisamente porque foi encontrada como aquilo que não cai sob o princípio de razão. Em várias passagens da obra completa, Schopenhauer ressalta que esse procedimento de estabelecer, "pela reflexão", a ligação entre "as duas fontes originariamente distintas de nosso conhecimento, a externa e a interna..." deve ser considerado o núcleo de sua doutrina (SCHOPEN- 
HAUER, 1972. Vol. IV, p. 91; cf. SCHOPENHAUER, 1972. Vol. II, p. 213, 201, 328, 678 s., Vol. I, p. 142) ${ }^{19}$.

Agora, decisivo é de que gênero é essa reflexão. Se ela ocorre segundo o princípio de contradição, a vontade é tomada como o fundamento da representação, e a representação é tomada como o fundamento da vontade, como motivo: o conhecimento está, assim, a serviço da vontade, e o egoísmo é, "do ponto de vista empírico, rigorosamente justificado" (SCHOPENHAUER, 1972.Vol IV, p. 266) - com todas as conseqüências amplamente exploradas por Schopenhauer para o desejo e para o sofrimento do homem.

Mas esse modo de ligar a experiência externa com a interna pela reflexão - tal como é efetuada, segundo Schopenhauer, na vida cotidiana - é inadequado. A vontade não pode ser compreendida segundo o princípio de razão como aquilo que está inteiramente excluído desse domínio de validade. A vontade individual determinada é, na Primeira consideração do mundo como vontade, transferida ao mundo por meio de abstrações e inferências, e, com isso, o conceito de vontade adquire uma extensão maior (SCHOPENHAUER, 1972. Vol. I, p. 132). Mas desta maneira não se compreende a vontade em sua generalidade; para tanto, teria de ser tomada imediatamente como mais geral. Como na passagem para a Segunda consideração, a lacuna que fica na compreensão é aqui preenchida mais uma vez por um novo modo de conhecimento, a saber, pela contemplação estética, que é o tema da Segunda consideração do mundo como vontade: "A representação considerada independentemente do princípio de razão”. Na contemplação estética, representações singulares não são reportadas à vontade individual, mas "a representação como um todo, o inteiro mundo intuitivo" é intuído na idéia como "objetividade adequada" da vontade (SCHOPENHAUER, 1972. Vol. I, p. 196, 206, 211 s). Essa intuição é, sem dúvida, algo inteiramente diverso da intuição condicionada pelo princípio de razão. Como modo de conhecimento do gênio, ela pressupõe um máximo de "lucidez" ou a inclui (SCHOPENHAUER, 1972.Vol.I, p. 219, Vol. II, p. 436 s; cf. KOBLER, 2002a). A lucidez torna possível que o conhecimento se "desembarace" da vontade e, assim, ao mesmo tempo, que o mundo como um todo, abarcando passado e futuro, seja apreendido em "um único olhar" [in Einem Blick] (SCHOPENHAUER, 1972.Vol. I, p. 209, 211). Nesse ponto 


\section{4}

Schopenhauer chega muito perto da intuição de Fichte, em quem encontrou também o conceito de "lucidez absoluta". A visão estética é “conhecimento puro" (SCHOPENHAUER, 1972.Vol. I, p. 221); é uma intuição que contém imediatamente em si uma reflexão, e de um modo tal que sujeito e objeto coincidem. Essa intuição não se refere, contudo, a si mesma, mas à vontade, que por ocasião de uma representação dada é apreendida como imagem perfeita, como idéia. Na medida em que o indivíduo aí "se esquece", ou seja, "perde-se" no intuído e torna-se mero "espelho" da vontade, é dado o mundo como autoconhe-cimento da vontade (SCHOPENHAUER, 1972. Vol. I, p. 210). Por isso, Schopenhauer também só fala do "autoconhecimento da vontade" no terceiro livro, e não já no segundo, em que é questão da autoconsciência imediata (SCHOPENHAUER, 1972.Vol. I, p. 196).

Uma vez que o conhecimento puro se refere à vontade que é experimentada no indivíduo, o autoconhecimento da vontade ainda não deixou para trás a estética. A vontade intuída objetivamente na idéia tem de ser unida à vontade subjetivamente experimentada no indivíduo. A imperfeição do conhecimento estético, que consiste em que a vontade individual apenas vem a ser esquecida na contemplação, manifesta-se na limitação temporal desse estado, após o qual imediatamente ressurge a vontade cotidiana. $\mathrm{O}$ vínculo da compreensão objetiva com a subjetiva é descrito na doutrina do caráter de Schopenhauer, segundo a qual o caráter individual se mostra na ação efetiva como realização determinada da idéia de homem, como realização determinada daquilo que o "homem em geral" quer (SCHOPENHAUER, 1972.Vol. I, p. 354 ss) ${ }^{20}$. A doutrina do caráter é o ponto central do sistema de Schopenhauer, ao qual podem ser reportadas todas as considerações feitas até aqui e tornadas compreensíveis unicamente por ele: a representação externa como ação; a experiência interna do ato da vontade como sentimento de imputação ao próprio caráter (sentimento de responsabilidade); e a referência à idéia como referência necessária às possibilidades humanas de ação em geral, que são o fundo ante o qual o caráter individual pode unicamente desenvolver-se. Demonstra-se, desta maneira, que a ordem do mundo físico, que na Primeira observação constitui o ponto de partida, é "dependente de um mundo moral” (SCHOPENHAUER, 1972. Vol. IV, p. 141). 
Esse autoconhecimento da vontade no caráter tem de ser, por sua vez, de gênero diferente do que está no fundamento das três observações feitas até aqui. Pois está imediatamente vinculado com a ação ${ }^{21}$.É apenas por sua ação efetiva que o homem experimenta seu próprio caráter, e cada ação modifica esse conhecimento. Com isso se chega ao momento da liberdade no autoconhecimento da vontade, mas não se trata aí da liberdade do indivíduo, pois esta é determinada pelo caráter. É, antes, a liberdade ou pela qual o indivíduo se torna caráter determinado ou pela qual, num paralelo com a contemplação estética - ele não se esquece, mas sim - se suprime. De acordo, o último livro, a Segunda consideração do mundo como vontade, intitula-se: "Afirmação e negação da vontade de viver uma vez alcançado o autoconhecimento". Afirmando ou negando, o homem se determina, na ação, a ser ou não caráter individual. Para ele, como indivíduo, as representações são motivos, como era o caso na Primeira consideração, mas agora são acompanhadas de reflexão, i. e., da consciência de que a afirmação que se exprime na ação determina o mundo tal como este se lhe oferece - a saber, como físico, caracterizado por desejos e sofrimentos. A ação do caráter possui, sem dúvida, uma conformidade à lei, contudo não há uma lei universal da razão como em Fichte, mas tão-só conformidade individual à lei. A ação moral mostra-se na negação desta última, na compaixão, à qual a individualidade cede o passo em face da idéia e, finalmente, na plena supressão do caráter mediante a negação da vontade de viver.

\section{A comparação entre os sistemas}

Por mais distintos que se mostrem, em sua elaboração, a "única intuição" de Fichte e o "único pensamento" de Schopenhauer, também aqui podem ser estabelecidos alguns traços concordantes. Ambos começam por uma consideração prévia de conhecimento que, no desenvolvimento posterior, se mostra como uma abstração, na qual a intuição é o primário e o pensamento o subordinado. No entanto, em ambos a reflexão, que também é designada como lucidez [Besonnenheit], desempenha o papel decisivo. Em Fichte, ela tem a função de "produzir" (SCHOPENHAUER, 1985.Vol. II, p. 89) a correlação entre a intuição 


\section{6}

fática e a superior e, em Schopenhauer, a de ligar a experiência externa e a interna. Em ambos, por fim, a reflexão os leva a considerar que o mundo físico ou mutável depende do moral, ou mais exatamente: que o mundo moral é a verdade do mundo físico.

Pode-se supor que Schopenhauer tenha sido inspirado por sua intensa ocupação com Fichte, a qual se cristalizou não apenas em suas anotações de aula, mas também em observações à margem e em notas sobre uma série de obras de Fichte, em particular sobre a Fundação de toda a Doutrina-da-Ciência e sobre o Sistema da doutrina ética (SCHOPENHAUER, 1985.Vol.V, p. 46 ss, 53 ss). Todavia, isso deve ter ocorrido, como também é possível ver em algumas observações feitas à margem da cópia do curso de Fichte de 1811/1812, de tal maneira, que os conceitos e as figuras da concepção de Fichte logo foram criativamente reinterpretados em um pensamento que repousa sobre fundamentos inteiramente diversos ${ }^{22}$.

Essa diferença tem sua raiz no conceito de intuição. A compreensão de Schopenhauer do conhecimento em geral repousa sobre a cisão entre sujeito e objeto, sendo a intuição especialmente marcada pelo principium individuationis, dado com as formas do espaço e do tempo. Essa compreensão exclui um saber do saber e uma auto-intuição; o autoconhecimento só pode ocorrer em relação a algo heterogêneo ao conhecimento, à vontade. $\mathrm{O}$ que à primeira vista aparece como a principal diferença, ou seja, que, em Fichte, se trata do saber, e, em Schopenhauer, da vontade, é apenas conseqüência de um conceito distinto de intuição. De acordo com o seu método, Schopenhauer permanece sempre na base da intuição empírica (no sentido mais amplo), mesmo quando, dessa maneira, avança a outros modos de conhecimento e, também, a uma intuição superior, que explodem os quadros de sua doutrina do conhecimento. Nesse sentido, Schopenhauer designa a sua filosofia como

metafisica "imanente" (SCHOPENHAUER, 1972.Vol.II, p. 736). Para a sistemática, isso significa que as quatros considerações de $O$ mundo como vontade e representação não podem ser derivadas umas das outras, mas se originam da mudança de perspectiva do mundo intuitivo. Schopenhauer, em uma série de passagens, descreve o seu procedimento metódico como variação de "ponto de vista" 23 . A cada ponto de vista tem de corresponder um fenômeno intuitivo, uma estado de coisas "empírico", aos quais

doispontos, Curitiba, São Carlos, vol. 4, n. 1, p. 153-173, abril, 2007 
pertencem também, para Schopenhauer, a experiência interna, a arte, a compaixão e a ascese. Essas perspectivas são reunidas pela reflexão, na medida em que os fenômenos são remetidos para a vontade como "chave de compreensão da essência em si das coisas" (SCHOPENHAUER, 1972. Vol. I, p. 140, cf. 119, 130, Vol. II, p. 204 s. et passim.). A reflexão permanece exterior aos fenômenos, e tomar em conjunto as remissões para um único pensamento (que não pode ser intuição) é o que "se exige" do leitor.

Em Fichte, em contraposição, desde o início a reflexão já está contida na intuição, mesmo que isso apenas se torne "visível" no decorrer da Doutrina-da-Ciência (SCHOPENHAUER, 1985. Vol. II, p. 90). No desenvolvimento do conceito de saber, a intuição fática emerge como intuição não-reflexionante, que tem de ser unida com o saber do saber, a intuição reflexionante. Também Fichte fala dos " 2 mundos sem correlação", correlação que é primeiro produzida pela Doutrina-da-Ciência (SCHOPENHAUER, 1985.Vol. II, p. 90). Mas, aqui, a reflexão unificante não permanece exterior, mas mostra-se como imanente ao saber. Mediante uma reflexão progressiva sobre o saber, a intuição fática é suprimida, e são "deduzidos", regressivamente, o múltiplo, o impulso e a vontade (Schopenhauer: 1985.Vol. II, p. 91). A relação com a intuição intelectual, a partir da qual se esclarece, como a partir de um "foco" (FICHTE, 1964. Vol. II, p. 178), todo o saber fático, não ocorre aqui como uma explicação do saber fáctico, mas sim como implicação recíproca. Que o leitor se eleve do saber fático e da experiência à reflexão e à intuição do saber absoluto, isso lhe é "exigido" por Fichte (FICHTE, 1964.Vol. II, p. 148)24.

O conceito de intuição de Fichte situa-se mais na tradição do racionalismo, ainda que a ordem do mundo que está no fundamento do saber seja não uma ordem divina, mas a própria lei da razão. O conceito de intuição de Schopenhauer situa-se mais na tradição do empirismo, ainda que, para ele, o empírico seja mais abrangente e inclua, ao lado da experiência interna, também os fenômenos estéticos e éticos. Alicerçando-se em tradições distintas, tentam harmonizar intuição e pensamento, tendo por resultado ou por escopo a demonstração de que o mundo físico repousa sobre o mundo moral e, por isso, pode ser apreendido e apresentado como sistema na filosofia. De acordo com distintos conceitos de intuição, os sistemas resultam inteiramente distintos, sem que seja excluí-

doispontos, Curitiba, São Carlos, vol. 4, n. 1, p. 153-173, abril, 2007 


\section{8}

da, com isso, a possibilidade de que possam tornar visível o mesmo pensamento ou intuição - caso se leve a sério o que diz Schopenhauer sobre a contradição entre matéria e forma da filosofia e a observação de Fichte de que a forma sistemática é apenas uma propriedade "contingente" da doutrina da ciência (FICHTE, 1964.Vol.I, p. 115). Não há dúvida de que a diferença formal tem conseqüências para a comunicabilidade [Mittelbarkeit] da filosofia (a espécie de "intuitibilidade" da exposição), para a sua relação com a ciência da natureza, com a arte e com a religião, conseqüências que, por fim, não podemos senão indicar de modo geral. É possível, contudo, que uma explicação mais exata das implicações mostre que, em filosofia, conteúdo e forma sistemática não podem ser assim separados, como assumem Fichte e Schopenhauer.

${ }^{2}$ A própria forma de fragmento é uma tentativa de solução, de Schlegel, que se afasta do sistema, tentativa essa que, preparada pelos escritos tardios de Schopenhauer, é levada adiante por Nietzsche. Sobre a questão do aforismo em Schopenhauer, que, contrariamente a uma visão muito difundida, permanece subordinada à concepção de sistema, cf. Sebastian Neumeister: Schopenhauer, Gracián und die Form des Aphorismus. In: SchopenhauerJahrbuch 85, 2004, p. 31-45.

${ }^{3}$ A passagem citada de Fichte encontra-se também traduzida, juntamente com a primeira parte da Exposição da Doutrina-da-Ciência, de 1801, in: Fichte, "A Doutrina-da-Ciência e o Saber Absoluto"; trad. Rubens R. T. Filho, Os Pensadores, São Paulo: Editora Nova Cultural, 1988, pp. 258-259. De resto, quando julgamos conveniente, adotamos dessa tradução uma ou outra solução; note-se, por fim, que a referida tradução traz "pensamento originário": Urgedanken, segundo o texto da edição das Obras Completas de Fichte, organizada por I. H. Fichte, ao passo que o presente artigo traz, na passagem citada, "não-pensamento": Ungedanken (N.T.).

4 Exceto em uma única ocorrência, traduzimos mitteilen por "compartilhar", em vez do usual "comunicar", a fim de manter a relação que tanto Fichte como Schopenhauer fazem, nos textos mobilizados neste artigo, entre mitteilen e as partes $<$ Teilen $>$ de um sistema originadas ao ser exposto (N.T.).

5 A passagem citada de Schopenhauer encontra-se também na tradução integral de O Mundo como Vontade e Representação. Trad. Jair Barbosa. São Paulo: Editora Unesp, 2005, pp. 19 e 20 (N.T.).

${ }^{6}$ Desse ano há, nos manuscritos póstumos de Schopenhauer, um esboço para uma introdução à sua filosofia que já contém os pontos essenciais de seus prefácios posteriores. Schopenhauer acredita apresentar, nesse esboço, uma sistemática completamente nova quando introduz os seguintes comentários: "já a partir daqui se pode entrever que talvez a filosofia aqui compartilhada seja diferente de todas as filosofias até agora, por mais diferentes que estas sejam, assim

doispontos, Curitiba, São Carlos, vol. 4, n. 1, p. 153-173, abril, 2007 
como são diferentes entre si 2 quaisquer das que existiram até agora" (SCHOPENHAUER, 1985, vol. 1, p. 387). Essa observação, que não foi publicada, seja porque Schopenhauer reviu sua concepção seja porque não era destinada ao público, fala ao menos contra uma adaptação consciente do pensamento fichteano acerca da concepção de sistema.

${ }^{7}$ A apresentação da cópia de Schopenhauer que é oferecida no prefácio da edição da Doutrina-da-ciência de 1812, em FICHTE, 1964, 13, p. 40 ss., é unilateral e, por isso, distorcida. Dos comentários de Schopenhauer são citados exclusivamente os polêmicos, com o intuito de corroborar o seguinte juízo geral: "Como nos é familiar nesse autor por seus escritos posteriores, também suas notas explicativas desta Doutrina-da-ciência estão repletas de menosprezo, calúnias e acusações”. Em contraposição, permanecem não citados os esporádicos comentários de aprovação de Schopenhauer e aqueles nos quais, como mostram os exemplos citados na nota 22 , ele lida de forma produtiva com as explicações de Fichte. A opinião de que, das cópias conservadas da Doutrina-da-Ciência de 1812, a de Schopenhauer seria "a pior", parece ser também determinada por essa unilateralidade, pois, na edição da preleção de 1812, a cópia de Schopenhauer é citada entre os quatros textos que foram considerados textos de base; contudo, segundo a advertência do editor (em FICHTE, 1964, IV, 4, p. 241 ss.), ela não foi levada em consideração numa nova publicação desse texto, pois este já se encontra disponível à pesquisa graças à reedição dos manuscritos póstumos de Schopenhauer.

${ }^{8}$ Ao lado da citação de Goethe, várias vezes empregada, aparece entre outras também esta de Shakespeare num comentário à margem: "Though this be madness yet there's method in it" ("Embora isso seja loucura, todavia possui método"; N.T).

9 Sobre a recepção de Fichte pelo jovem Schopenhauer, cf. KAMATA, 1988; sobre o curso de 1811/12, em particular p. 119 e ss., 134, 137, 151 e s., 172, 205 e ss.

10 De resto, na crítica ao princípio da intuição intelectual, Schopenhauer vai ao encontro de Hegel, que aponta, no mesmo sentido, nas Lições sobre a história da filosofia, o "defeito da filosofia de Schelling": "quando se filosofa que é deste modo, pretende-se que foi demonstrado. Mas se se começa com a intuição intelectual, então a asserção é um oráculo que se deve acatar, porque é feita a exigência de que se intua intelectualmente" (HEGEL, 1971, vol. 20, p. 435; sobre Fichte, cf. tb. HEGEL, 1971, vol. 5, p. 76 ff.). Cf. tb. WELSEN, 1997, p. 31-61.

11 Aí, Fichte designa como "relâmpago da evidência" esse apreender em um único olhar, o que Schopenhauer comenta com as seguintes palavras:"Ele alcançou, assim, a infalibilidade!".

12 Fichte demarca a maneira do manter-juntos pela intuição como "fundir", no contraste tanto com o "reunir" quanto com o "dispersar", "pois não há unidade senão a dos separados, e não há separados senão na unidade” (FICHTE, 1964.Vol. II, p. 152).

13 O determinar é tomado aqui como "quantificar"; a determinabilidade, como "quantificabilidade”. Cf. SCHRADER, 1989, em partic. p. 209 s.

14 FICHTE, 1964.Vol.II, p. 186, 226; cf. tb. p. 295: “em rigor, a expressão mundo dos sentidos envolve uma contradição. Na verdade, não há aqui nenhum universo, nenhuma totalidade, mas infinitude flutuante, que jamais é apreendida. Universo só há para o pensamento, mas então é um universo moral".

doispontos, Curitiba, São Carlos, vol. 4, n. 1, p. 153-173, abril, 2007 


\section{0}

15 Cf. FICHTE, 1964.Vol. I, p. 203; SCHOPENHAUER, 1985.Vol.II, p. 84: “O saber fático, tão certo ele o seja, não se vê a si; e tão certo que se veja a si, ele não é”; p. 92 s.: “... a reflexão destrói a realidade".

16 Essa segunda passagem relevante acerca do "um único pensamento" na obra publicada de Schopenhauer não contém, diferentemente do prefácio, nenhuma explicação adicional. Apenas que, no lugar do "conselho" vago para que o livro "seja lido duas vezes" (p. VIII), aparece "a exigência" ao leitor, um tanto mais concreta, de que "se lembre não apenas do que acabou de ser dito, mas também de tudo o que fora dito antes, de modo que seja capaz de ligá-lo com o que está a cada vez presente, por mais que alguma coisa se interponha entre um e outro". Sobre a função sistemática da "exigência” em comparação com Hegel, cf. KOßLER, 1990, p. 156 ss.

17 SCHOPENHAUER, 1972.Vol. I, p. 13 e cf. p. 53: “Assim, a nossa habitual intuição empírica é uma intuição intelectual, e é a ela que convém este predicado que os filósofos fanfarrões na Alemanha atribuíram à suposta intuição de mundos oníricos, onde o amado absoluto deles realiza suas evoluções”. Em WELSEN (loc. cit., p. 53; cf. n. 15), encontra-se outra série de passagens em que Schopenhauer critica a intuição intelectual no idealismo alemão.

18 Mesmo numa mera exposição abreviada, deve-se assinalar, uma vez que é muitas vezes ignorado, que o conhecimento da vontade por meio da experiência corporal e a inferência ao ser das coisas são essencialmente mais complicados e exigem, como enfatiza Schopenhauer, "uma pesquisa mais profunda, uma abstração mais dificil, uma separação do diferente e uma unificação do idêntico" (SCHOPENHAUER, 1972.Vol. I, p. 5). Constitui o ponto de partida a consciência do ato voluntário individual em uma ação consciente, no qual a vontade "se anuncia, mas não inteiramente"; falar de "vontade" já pressupõe uma "aplicação da reflexão" (SCHOPENHAUER, 1972.Vol. I, p. 130 s.).

19 Sobre esse ponto, cf. tb. FICHTE, 1964.Vol. II, p. 311, onde ele primeiro segue de ponta a ponta o "mundo da empiria desde o seu próprio chão até o seu ponto fundamental supremo, no qual ele se perde para o olho empírico" e, em seguida, começa "do outro lado", i. e., do lado do "puro eu absoluto". Nos seguintes excertos da Doutrina-da-Ciência aparece outra série inteira de teses que são reencontradas em Schopenhauer com semelhança textual integral: o eu como "suporte" do mundo (p. 311), o solipsismo teórico e o prático (p. 314), a distinção meramente "numérica" (cf. o principium individuationis de Schopenhauer) e a "distinção real dos indivíduos" (p. 315), todos os quais estão vinculados, como em Schopenhauer, à idéia e ao caráter inteligível, cuja determinidade é a da "ação do indivíduo, a qual independe de toda percepção e antecede toda percepção" (p. 316). No entanto, essas determinações são desenvolvidas em Fichte no quadro do mundo moral, no quadro de um "sistema do ser racional" (p. 360) e têm, por isso, um significado totalmente diverso do que possuem em Schopenhauer. Isso se torna particularmente claro em uma passagem na qual parece existir uma grande concordância com Schopenhauer quando Fichte escreve: "Se se fala de um mundo melhor e das marcas da benevolência de Deus neste mundo, então a resposta é: o mundo é de longe o pior que pode existir, se é que ainda deva haver mundo"; mas continua logo a seguir, opondo-se inteiramente a Schopenhauer: "mas precisamente por isso está disseminada no mundo toda a benevolência de Deus unicamente possível, de modo que a partir deste mundo a inteligência pode elevar-se à resolução de torná-lo melhor" (p. 320). Dado que no presente

doispontos, Curitiba, São Carlos, vol. 4, n. 1, p. 153-173, abril, 2007 
artigo está em primeiro plano a questão do sistema e do método, a relação entre Schopenhauer e Fichte do ponto de vista do conteúdo não pode ser senão indicada. Dos trabalhos mais recentes sobre o tema, cf. WELSEN, 1997; SCHÖNDORF, 1982; DECHER, 1990. Uma investigação abrangente ainda está por ser feita.

20 Para mais pormenores sobre a doutrina do caráter, apresentada aqui apenas de modo sumário, cf. Matthias KOBLER, 2002b.

21 SCHOPENHAUER, 1972.Vol IV, p. 60: "por nossa ação experimentamos apenas o que somos";Vol. I, p. 354: "Só há ato porque via de regra o homem é senhor de sua razão, é refletido, portanto, ... o resultado de seu querer mais íntimo e constitui-se como uma letra em uma palavra, que assinala seu caráter empírico, o qual não é senão a expressão temporal de seu caráter inteligível".

22 Nesse sentido, Schopenhauer faz a seguinte observação sobre um excerto da preleção de Fichte em que este diz que a decisão de passar da reprodução para a percepção, por não pertencer a nenhuma das duas, tem de ser "atemporal": "pode-se dizer que a decisão tem de estar fora de todo o tempo, uma vez que ela é um ato da vontade, que, como uma coisa em si, está para além de todo o tempo" (SCHOPENHAUER, 1985.Vol. II, p. 215). Nesse excerto, Fichte não fala da vontade, e a coisa em si evidentemente não tem lugar algum em sua filosofia. Schopenhauer, porém, liga o motivo da atemporalidade da decisão a uma interpretação peculiar da coisa em si kantiana. Em contraposição, onde Fichte tem como tema, na preleção, a vontade, dizendo, por exemplo, que "todo ser está no ponto de unidade da vontade" (SCHOPENHAUER, 1985. Vol. II, p. 215), não se verifica nenhum interesse de Schopenhauer. Outro exemplo é a retomada do conceito de "lucidez absoluta", sobre a qual escreve Schopenhauer: "O ponto de lucidez absoluta, para o qual F[ichte] quer conduzi-los [os ouvintes], é, como me parece, o ponto de uma consciência que por si é subsistente, independente da percepção e não dada por esta, a partir do qual procede o estranhamento filosófico sobre o mundo, i. e., sobre aquela segunda consciência na percepção (consciência essa que, para o senso comum, é a única)" (SCHOPENHAUER, 1985.Vol. II, p. 30 s.). É interessante ver a mudança que Schopenhauer confere à "lucidez absoluta" de Fichte. Fichte designa por ela uma reflexão do saber sobre si mesmo, um perceber ou tornar-se consciente do perceber como tal e no todo. Isso se torna, em Schopenhauer, uma consciência inteiramente distinta, que não reflete sobre a percepção, i. e, sobre a consciência comum, mas simplesmente a nega; é uma consciência "inteiramente diferente" desta última. É possível ver uma ligação dessa interpretação da lucidez absoluta com a chamada doutrina da "consciência melhor", que pode ser encontrada entre 1812 e 1814 nos primeiros manuscritos de Schopenhauer, mas já está preparada nos esboços mais antigos desde 1804.

23 SCHOPENHAUER, 1972.Vol.II, p. 206, 541, P I, p. 100 et passim.; cf.Vol.VI, p. 13: "Não pode ser completamente falsa nenhuma visão do mundo que se originou de uma apreensão objetiva, intuitiva das coisas, e foi levada adiante de maneira conseqüente; no pior dos casos, é somente unilateral: como, por exemplo, o materialismo mais perfeito, o idealismo absoluto etc. são todos verdadeiros; mas o são ao mesmo tempo: a verdade deles é, por conseguinte, apenas uma verdade relativa. Cada uma dessas apreensões só é verdadeira de um determinado ponto de vista". Quando se saiu de tal ponto de vista determinado, então "se deve, em seguida, mudar de ponto de vista e assumir o ponto de vista contrário, do qual de novo se deduz aquilo que, num filosofema que o complementa, foi tomado inicialmente como dado" (Vol.

doispontos, Curitiba, São Carlos, vol. 4, n. 1, p. 153-173, abril, 2007 


\section{2}

IV, p. 35). Cf. SPIERLING, 1998, p. 223 ss., que, baseando-se em semelhantes expressões de Schopenhauer, desenvolve em sua interpretação a "figura do método da revolução copernicana da variação". Concordando em princípio com a caracterização do método de Schopenhauer como variação de ponto de vista, a interpretação aqui apresentada difere da de Spierling, uma vez que este não relaciona os pontos de vista com as partes do sistema, mas assinala a cada vez, no interior das partes (em que a Estética se sobressai), a "variação complementar dos pontos de vista", que giram e se movem uns em torno dos outros (p. 224).

24 Cf. tb. FICHTE, 1964.Vol. I, 3, p. 146: "Mas a Doutrina-da-ciência, como ciência, simplesmente não inquire a experiência e de modo algum a leva em consideração. Teria de ser verdadeira mesmo que não houvesse nenhuma experiência...".

\section{Referências bibliográficas}

DECHER, F. 1990. "Schopenhauer und Fichtes Schrift, Die

Bestimmung des Menschen”". In: Schopenhauer-Jahrbuch 71 (p. 45-67).

FICHTE, J. G. 1964. Gesamtausgabe der Bayerischen Akademie der

Wissenschaften. Stuttgart-Bad Cannstatt: Friedrich Frommann.

HEGEL, 1971. Werke in zwanzig Bänden. Frankfurt/M: Suhrkamp.

KAMATA,Y.1988. Der junge Schopenhauer. Genese des Grundgedankens der Welt als Wille und Vorstellung. Freiburg / München.

KANT, I., 1968. Akademie-Ausgabe. Berlim:Walter de Gruyter

KOßLER, M. 1990. Substantielles Wissen und subjektives Handeln, dargestellt in einem Vergleich von Hegel und Schopenhauer. Peter Lang: Frankfurt/Bern/New York/Paris.

KOßLER, M. 2002a. "Zur Rolle der Besonnenheit in der Asthetik Arthur Schopenhauers”, in Schopenhauers-Jahrbuch, 83 (p. 119-133).

KOßLER, M., 2002b. "Schopenhauers Philosophie als Erfahrung des Charakters", in: Dieter Birnbacher, Andreas Lorenz, Leon- Miodonski (Hrsg.): Schopenhauer im Kontext. Deutsch-polnisches SchopenhauerSymposium 2000. Würzburg: Königshausen u. Neumann, pp. 91-110.

RITTER, JOACHIM E GRÜNDER, KARL. 1971. "System” in: Historisches Wörterbuch der Philosophie. Basiléia-Stuttgart:Schwabe und Co.Verlag. 
SCHRADER, W. 1989 "Der Übergang zur Wissenschaftslehre 1801”. In: Albert Mues (Hg.): Transzendentalphilosophie als System. Die Auseinandersetzung zwischen 1794 und 1806,. p. 199-211. Hamburg: Meiner.

SCHLEGEL, F. 1980. Werke in Zwei Bänden. Berlin: Aufbau-Verlag SCHÖNDORF, H. 1982. Der Leib im Denken Schopenhauers und Fichtes. München.

SCHOPENHAUER, 1972, Sämtliche Werke. Ed Arthur Hübscher . Munique: Wiesbaden, Brockhaus.

SCHOPENHAUER, 1985. Der handschriftliche Nachlass in fünf Bänden. Ed. Arthur Hübscher Munique: Deutscher Taschenbuch Verlag GmbH \& Co.

SPIERLING,V. 1998. Arthur Schopenhauer. Eine Einführung in Leben und Werk. Leipzig: Reclam.

WELSEN, P. 1997. “'Ein sehr wunderliches Ding, sehr wunderlich dargestellt' - die transzendentale Apperzeption bei Kant, Fichte und Schopenhauer". In: Schopenhauer-Jahrbuch 78. 
174

○

0 